\title{
The role of empathy in case management: a pilot study
}

\section{Elisabeth Engelberg \& Arthur Limbach-Reich}

To cite this article: Elisabeth Engelberg \& Arthur Limbach-Reich (2015) The role of empathy in case management: a pilot study, Social Work Education, 34:8, 1021-1033, DOI: 10.1080/02615479.2015.1087996

To link to this article: http://dx.doi.org/10.1080/02615479.2015.1087996

\section{曲 Published online: 02 Nov 2015.}

Submit your article to this journal $\lceil\pi$

山 Article views: 10

Q View related articles $\sqsubset$

View Crossmark data ¿ 


\section{The role of empathy in case management: a pilot study}

\section{Elisabeth Engelberg* \& Arthur Limbach-Reich}

${ }^{a}$ Institute for Research and Innovation in Social Work, Social Pedagogy, Social Welfare (IRISS), University of Luxembourg, Walferdange L-7201, Luxembourg

Little research has been done on the benefit of empathy for social workers in the actual practice of their profession. This prompted an exploration of the interplay between empathic ability and the skills practitioners draw on for case management. Two cohorts of social work students, in their final semester, reflected on an authentic social work scenario and suggested a plan for intervention before completing a scale measuring empathy. The results revealed that different dimensions of empathy, to a varying degree, underpin the process through which students come to a decision on how to intervene. The findings provide empirical support for the assumption that empathy plays an essential role in the practice of social work. They also suggest the need for further investigation, particularly given the potential use of increased knowledge on what determines the skills needed to take on the oftentimes complex and demanding reality of social work.

Keywords: Empathy; competency; curriculum development

In recent studies, researchers have called for closer attention to be paid to empathy in the education of social workers and in the practice of social work (Gair, 2013; Gausel, 2011; Gerdes \& Segal, 2011; Grant, 2014; Hen \& Goroshit, 2011; Napoli \& Bonifas, 2011). There is a good reason to claim that empathy is an advantage in the anti-oppressive practice of social work, which is intended to help people in various situations of distress, dysfunction or deadlock. There is already some empirical support for this assumption based on observations of communication (Forrester, McCambridge, Waissbein, \& Rollnick, 2008; Nijnatten, Hoogsteder, \& Suurmond, 2001) and care provision (Barlow \& Hall, 2007; Buckley, 1986).

Nonetheless, a question remains on what role empathy might play in the execution of other social work tasks, such as case management. Interpersonal skills are after all but one vital part of a professional's overall competence. Of equal importance are analytic ability, evaluation and strategic planning (Galuske, 2011;

^Corresponding author. Email: Elisabeth.Engelberg@uni.lu 
Maus, Nodes, \& Röh, 2008; Morrison, 2007) and, more importantly, the ability to solve problems while dealing with complexity, ambiguity and uncertainty (Lymbery, 2003). It seems obvious that the social worker has to pit the requirement of being receptive to the feelings and motives of others against that of maintaining some degree of objectivity.

The present article briefly reviews the concept of empathy on the basis of psychological theory and research. It further reports the findings of a pilot study exploring the interplay between empathy and the skill that practitioners draw upon when prioritizing different steps of an intervention in a service user case.

\section{Empathy}

One of the early definitions of empathy focused on one person's 'feeling into' the subjective state of another person (Lipps, 1913). By contrast, Kohler (1929) was one of the first to argue that empathy was actually a matter of understanding the experience of another person rather than sharing that person's emotions. Since that time, various investigations of the phenomenon have been carried out in an attempt to come to a more comprehensive conclusion with regard to the nature of empathy. In the helping professions, it has been of particular interest to define the concept, the aim being to gain insight into how empathy could be meaningfully taught and applied in practice.

Such attempts have suggested the existence of both reflective and affective dimensions of empathy. The literature reveals how the emphasis has invariably been placed on the care provider's ability to understand care recipients' inner world and concerns (Gallagher, 2006) as well as the care provider's ability to vicariously share care recipients' emotional experience (Buie, 1981). However; the distinction between the more reflective as opposed to the affective kind of empathy is of further relevance to social work education in view of the significant implications for the relationship between caretakers and providers. With the former, intellectual stance, the practitioner can maintain emotional distance (Dyregrov \& Mitchell, 1992), while with the latter, there is a risk for emotional exhaustion and impaired professional judgement (Fahy, 2007), although some argue that both dimensions are needed to ensure positive client outcomes (Wampold, 2010).

It is evident from the psychological literature that scholars typically agree on the conceptualization of empathy as being a two-dimensional phenomenon (Coke, Batson, \& McDavis, 1978; Decety \& Jackson, 2004). Mark Davis (1983a) further elaborated on the concept of empathy by outlining a set of constructs, each of which captures some essentially different facet of the phenomenon: Perspective Taking and Fantasy represent the reflective component of empathy, whereas Empathic Concern and Personal Distress represent tendencies to engage in emotional responses. These subcomponents will be briefly reviewed before explaining the pilot study in greater detail. 
Perspective taking

A prerequisite for empathy should be an understanding of another person's point of view or situation (Davis, 1983a). In this sense, perspective taking is the cognitive ability needed to initiate and control the mental processes whereby people can adequately grasp the details that define the situation of another person (Chambers \& Davis, 2012; Davis, Conklin, Smith, \& Luce, 1996). This view has evolved from the early conceptualization of this empathy dimension as the ability to subordinate the perspective of one's own self to that of a larger group (Marvin, Greenberg, \& Mossler, 1976). In support of this view, findings suggest that high levels of perspective taking tend to be linked to the propensity to be mindful of how a situation is experienced by other persons involved (Davis, 1983a; Galinsky, Ku, \& Wang, 2005). In this regard, perspective taking should be an essential precondition for the ability to comprehend how conflicts within interpersonal interactions can arise and for recognizing suitable approaches to such information.

\section{Fantasy}

Another prerequisite for empathy should be a willingness to project oneself into the feelings and actions of another person (Lee, Guajardo, Short, \& King, 2010). This propensity increases a sense of self-other overlap by merging mental representations of the self and of the other person in a way that creates a sense of similarity (Davis et al., 1996). Such partial identification with another person may entail the ability to vicariously experience the situation of that person, as suggested by the finding that people who score high on fantasy tend to be more sensitive to others and to be slightly more susceptible to emotional responses (Davis, 1983a). The concept of fantasy originally refers to people's propensity to get involved in fictional situations and to identify with characters in books, movies or stage plays. Recent research has established, however, that the concept of fantasy is just as viable in relation to empathy for real persons as it is in relation to empathy for fictional characters (Nomura \& Akai, 2012).

\section{Empathic concern}

Empathic concern corresponds to the tendency to sympathize with or feel protective towards others who are less fortunate or treated unfairly. Sympathy and empathy are often used synonymously; however, sympathy involves more specifically the sharing of emotions that are experienced by another person (Wispé, 1986). The literature reveals an impressive programme of research suggesting that empathy is linked to helping behaviour (Batson, Turk, Shaw, \& Klein, 1995; Davis, 1983b), particularly when feelings of sympathy and compassion are evoked (Eisenberg, 2000). The level of such deep concern increases when one can imagine being in the place of another person, as opposed to when one adopts a detached point of view (Batson, Early, \& Salvarani, 1997; Coke et al., 1978). Empathic concern then affects helping behaviour primarily through the perception of sharing the emotional state of the other person (Cialdini, Brown, Lewis, Luxe, \& Neuberg, 1997). 


\section{Personal distress}

By contrast, the observer of another person's plight could be overcome with feelings of dismay and shock, which are qualitatively different from the affect of empathic concern. Whereas empathy is generally linked to altruistic motivation to help, distress is linked to egoistic motivation to reduce one's own aversive arousal. Physical escape from exposure to the suffering of another person may enable mental relief (Toi \& Batson, 1982). People who score high on personal distress have been found to be prone to feelings of vulnerability, uncertainty and fearfulness (Davis, 1983a). Presumably for these reasons, it has been found that the more intense the experience of personal distress, the less likely the inclination to engage in helping behaviour (Carrera et al., 2013; Davis, 1983c).

The four constructs capture related, yet distinct aspects of empathy, where each enables a more detailed analysis of the role of empathy in the practice of social work. To date, there is published work on the role of emotional competencies for stress management in social work (Kinman \& Grant, 2011) as well as research on teaching empathy-related skills, such as mindfulness (Grant, 2014; Napoli \& Bonifas, 2011) and emotion management (Hen \& Goroshit, 2011), to social work students. There is, however, to our knowledge no research specifically examining the interplay that presumably exists between the various aspects of empathy and decision-making with regard to how to intervene in service user cases. In order to begin to explore this interplay, the present pilot study was conducted.

\section{Purpose of the study}

The present study investigated whether and how empathy underpins the ability to go about case management in a manner consistent with proficient practice. Here, the notion of 'proficient practice' refers to the decision-making process by which experienced practitioners handle service user cases and the resultant outcome.

Based on extant literature, we expected the abilities of perspective taking, fantasy and empathic concern, to be associated with the decision for an intervention that prioritizes proper assistance. Such a decision should not benefit from personal distress, given that this propensity reflects the inclination to distance oneself from another person's predicament. In short, we hypothesized that the decision to provide proper assistance would draw upon the abilities to view a situation from the perspective of the people involved, to understand their feelings and actions and to feel concern for them without experiencing distress.

This hypothesis was tested while evaluating readiness to practise among social work students in their final semester. To this end, we used an instrument that requires students to consider an authentic social work scenario and to respond to it by appropriate decision-making (see MacIntyre et al., 2011). 


\section{Method}

\section{Respondents}

The respondents consisted of two cohorts of students (Ns = 29 and 30) with 46 weeks left until they would graduate with a bachelor's degree in social work (50 women, 9 men). They were asked to complete a questionnaire during one of their scheduled lectures. In order to ensure their anonymity, they were instructed to hand in the questionnaire without recording either name or student registration number on it. They were accurately informed that their effort would provide helpful input to the overall evaluation of the study programme (see Engelberg \& Limbach-Reich, 2012, 2015). All students opted to participate and completed the questionnaire in full.

\section{Questionnaire}

The questionnaire was used to present a case description to the students who were subsequently asked to respond to three open-ended questions. These questions aimed at collecting data to assess the extent to which the students processed the information of the case and took proficient decisions upon an intervention strategy. The vignette and the open-ended questions were thus used to measure the same concept, i.e. decision-making strategy in relation to level of probing and performance. In addition, data were collected to measure the students' ability for empathy.

The respondent was instructed to read through the description of an authentic social work case that had recently been handled by the social services in the same country and region where he/she went to university. Before presenting the vignette to the students, details that risked revealing the identity of the service users were either changed or omitted.

The case described a family situation bereft with problems linked to marital conflict, sporadic school attendance, ADHD, alcohol/drug abuse and violent behaviour. The vignette was tested prior to the study by presenting it separately to each of four social workers with 10-15 years of professional experience in the social service sector. Their input served as a guideline when assessing the data that were to be collected using this particular vignette. More specifically, the focus of the intervention was to provide immediate support to one of the siblings in the family, who will henceforth be referred to as P. The subsequent step of the intervention was to provide long-term assistance to the family as a whole, which consisted of P's parents, siblings and grandmother.

\section{Level of probing}

The first and second of the open-ended questions read as follows: 'What facts in the case description do you consider to be significant?' and 'What information do 
you think is missing, that is, information that would allow you to explain what is going on in the situation?' These two questions aimed at capturing the extent to which the respondent demonstrated an effort to probe the problem and to reflect on it. This ability was scored on a three-point scale, where 1 denoted a descriptive level of merely describing or reiterating the content of the case description, 2 denoted analytic skills in elaborating on what is happening and the likely reasons why and 3 denoted reflective skills associated with drawing on theory and questioning the information given in the case description. In short, a higher score on these open-ended questions signifies a greater capacity to process the information in a skilful and purposeful manner.

\section{Performance}

The third question read as follows: 'As the social worker, what could you do in this situation?' This question aimed at examining what interventions the respondents emphasized. This data were scored according to the following criteria: (1) helping the person P, (2) helping the family and (3) further assessment by involving other professionals. Each of these criteria was rated on a four-point scale where 1 denoted 'not mentioned at all'; 2 'barely mentioned'; 3 'mentioned' and 4 'strongly mentioned'. A higher score on any of these vignette performance measures, that is, Help P; Help Family and Assessment, signifies the decision to pursue this particular mode as intervention.

\section{Empathy}

Upon completion of the open-ended questions, students were instructed to fill out a short battery of questions, which corresponded to the Interpersonal Reactivity Index (IRI; Davis, 1980). This inventory is one of the most common questionnaires used to measure self-reported empathic tendencies in adults. In order to accommodate to the students' mother tongue, the German version of the IRI (Paulus, 2009) was administrated.

The IRI captures the different facets of empathy with four items for each of the subscales, which are Perspective Taking $(=.69)$, Fantasy $(=.78)$, Empathic Concern $(=.77)$ and Personal Distress $(=.66)$. The total of 16 items are statements that the respondent rates on a five-point scale $(1=$ never; $5=$ always). The higher the respondent's score on any of the subscales, the higher is his or her propensity for that particular aspect of empathy.

For the hypothesis testing, the subscales of Perspective Taking, Fantasy, and Empathic Concern, were added into a Composite Empathy Score $(M=3.53$, $\mathrm{SD}=0.42$, = .73). The remaining IRI subscale of Personal Distress was treated separately in the analyses, due to the discrepant conceptual content in relation to those of the other subscales, as evident through prior research reviewed above. 


\section{Results}

\section{Level of probing}

The first analysis aimed at assessing the extent to which respondents processed the vignette information. The mean value was $1.56(\mathrm{SD}=0.70)$, which suggests that the students were mainly analytical in their efforts to probe the information. Using Pearson's correlation coefficient, the level of probing was examined in relation to the three vignette performance measures. As shown in Table 1, this analysis revealed that a more skilled probing of the vignette information was linked to the explicit decision to help $\mathrm{P}$, that is, the person who was in the most immediate need of support in this service user group. The correlations to the four subscales of empathy further revealed that probing was strongly linked to perspective taking and fantasy, which suggests that a more qualified processing of case information is associated with higher propensity for cognitive or reflective abilities of empathy.

\section{Performance}

The second analysis aimed at examining the relations between the vignette performance measures and the four subscales of empathy. The mean values, along with the intercorrelations, are presented in Table 1. As expected, there was a tendency for perspective taking, fantasy and empathic concern, to be positively related to the respective decisions to help $\mathrm{P}$ and the family, and negatively related to assessment, or the decision to involve other professionals for further evaluation. Conversely, there was a tendency for personal distress to be negatively correlated to the three performance measures.

Table 1 Mean values and intercorrelations between the vignette measures and subscales of empathy

\begin{tabular}{|c|c|c|c|c|c|c|c|c|c|c|}
\hline & $M$ & $\mathrm{SD}$ & 1. & 2. & 3. & 4. & 5. & 6. & 7. & 8. \\
\hline 1. Probing & 1.56 & 0.70 & - & & & & & & & \\
\hline 2. Help P & 2.46 & 1.24 & $.32^{*}$ & - & & & & & & \\
\hline 3. Help Family & 1.88 & 1.02 & .16 & $.46^{\star \star}$ & - & & & & & \\
\hline 4. Assessment & 2.13 & 1.32 & -.06 & -.12 & -.22 & - & & & & \\
\hline 5. Perspective Taking & 3.82 & 0.46 & $.32^{\star}$ & .19 & .13 & .03 & - & & & \\
\hline 6. Fantasy & 3.18 & 0.67 & $.31^{\star}$ & $.28^{*}$ & .21 & $-.44^{* *}$ & -.13 & - & & \\
\hline 7. Emphatic Concern & 3.61 & 0.55 & .06 & .17 & .16 & $-.31^{\star}$ & .09 & .17 & - & \\
\hline 8. Personal Distress & 2.49 & 0.53 & -.01 & $-.40^{\star \star}$ & -.04 & -.16 & $-.26^{\star}$ & .20 & $.28^{\star}$ & - \\
\hline
\end{tabular}

${ }^{*} p<.05 ;{ }^{* *} p<.01$. 
Table 2 Model summaries and regression coefficients for the composite empathy score and the subscale of personal distress predicting scores on three vignette performance measures $(\mathrm{df}=1.57)$.

\begin{tabular}{|c|c|c|c|c|c|c|c|c|c|}
\hline & \multicolumn{3}{|c|}{ Help P } & \multicolumn{3}{|c|}{ Help Family } & \multicolumn{3}{|c|}{ Assessment } \\
\hline & $F$ & $R^{2}$ & $b$ & $F$ & $R^{2}$ & $b$ & $F$ & $R^{2}$ & $b$ \\
\hline Composite Empathy Score & 10.18 & $.15^{\star \star}$ & .62 & 5.57 & $.09^{*}$ & .39 & 12.37 & $.18^{\star * *}$ & -.71 \\
\hline Personal Distress & 10.90 & $.16^{\star *}$ & -.92 & 0.10 & .002 & -.08 & 1.66 & .03 & -.41 \\
\hline
\end{tabular}

\section{Hypothesis testing}

Each of the performance measures was analysed to test the hypothesis that empathy underpins a proficient decision on an intervention plan. In view of the sample size (Green, 1991), bivariate regression was chosen as statistical method. The composite empathy score and the personal distress subscale, respectively, were entered into separate regression analyses as the predictor variable.

As seen in Table 2, the analysis on Help $\mathrm{P}$ as the criterion variable yielded a significant result, which suggests a strong association with the composite empathy score. This result suggests, more specifically, that higher levels of empathic ability are linked to the likelihood of identifying the person who is in the most immediate need of help in the particular service user group. The analysis on Help Family as the criterion variable similarly showed a positive association with the composite score. By contrast, the analysis on assessment, i.e. the decision for further evaluation, showed a strong, negative association to the composite score. The overall finding from these analyses is that the composite empathy score emerged as significant over the three performance measures.

Results for the analyses with personal distress as the criterion variable are shown in the second row of Table 2. There was a negative relation between Help P and this subscale, suggesting that proficient decision-making in the social work practice is associated with lower levels of emotional distress. However, the associations were non-significant between this subscale and the respective vignette measures of Help Family and Assessment.

\section{Discussion}

The present findings were basically in line with our expectations, as they clearly suggest that the students drew upon empathy in responding to the case vignette. In other words, empathic ability was shown to underlie the process by which a service user case was managed in accordance with proficient practice.

There are two features of the results that stand out in support of the assumption that empathy is essential to the social work practice. The first feature pertains to the results that Help $\mathrm{P}$ and Help Family drew positively on the composite 
empathy score, while the reverse was found with regard to further Assessment by involving other professionals (see Table 2). It suggests that prioritizing proper assistance generally hinges on the ability to understand and relate to other people and their situation. The implication is ultimately that empathy plays an important role in what lies at the heart of the social workers' mission; to enhance human well-being with particular attention to the needs and empowerment of the most vulnerable (National Association of Social Workers, 2008).

The second feature pertains to how personal distress was shown to emerge in a significant fashion only in relation to the performance measure of Help P (see Table 2). This result suggests that proficient decision-making is incompatible with the propensity to experience emotional distress in the face of another person's predicament. The finding thus seems to accord with studies highlighting the value of emotion management; for example, the importance of reflective abilities for tempering empathic distress (Grant, 2014), and perhaps also of mindfulness for controlling impulsivity and reactivity in relations with service users (Napoli \& Bonifas, 2011). It fundamentally seems to point to the benefit of a level-headed approach in balancing the vicarious experience of another person's emotions and the reflective effort needed to understand his/her situation, as one way of preventing the professional hazards of compassion fatigue and burnout (Coyle, Edwards, Hannigan, Fothergill, \& Burnard, 2005; Fahy, 2007).

It is possible, though, that personal distress emerged in a negative fashion simply because respondents learned the details of the case through reading, rather than through personal contact with the actual service users. It has been argued that vignettes do not fully capture how people's assessments and reactions typically arise when they result from an ongoing dialogue with the environment (Parkinson \& Manstead, 1993). By contrast, others argue that vignettes provide an unobtrusive means of eliciting information about people's thought processes (Poulou, 2001), which was the basic aim of the present study, that is, to investigate the analysis and decision-making processes that social workers engage in when they manage service user cases. In any event, we may have been able to make a closer approximation of reality had we used virtual reality vignettes (see Paschall, Fishbein, Hubal, \& Eldreth, 2005).

Although the methodology used here cannot fully reproduce the reality of practice, there is evidence that affective empathy can be evoked through the deliberate exercise of cognitive empathy. Experimental studies have shown that participants who were instructed to only take the point of view of a particular person reported greater empathic concern (Davis, 1983b; Toi \& Batson, 1982), or other congruent emotional reactions to this person (Davis, Hull, Young, \& Warren, 1987), than participants who did not receive these instructions. The vignette should therefore have been adequate for the present purposes, because the respondents, who were unaware that their empathic ability was being assessed, did not receive any such instructions, and therefore presumably made efforts at perspective taking on their own accord. 
Given the premise of our rationale, the issue of nature versus nurture is raised. Do social workers tend to draw more on empathy than people in other professions? Scholars typically conceptualize empathy as a stable trait, thereby adhering to the view that some individuals are more empathic than others, either by nature (Mooradian, Davis, \& Matzler, 2011) or as a result of their development (Georgi, Petermann, \& Schipper, 2014). In this connection, it would have been interesting to compare the IRI scores of our respondents to those of a group of undergraduate students at the same university, but studying something other than social work. Yet, the question would still remain as to whether social work students would presumably tend to score higher on empathy due to their natural disposition for empathy or due to the bachelor's programme they are attending, or perhaps both.

The discussion on empathy as a disposition or trained ability has interesting implications for both education and research. For instance, should students be asked upon enrolment to fill out an inventory measuring empathy-related skills? Such information would likely enable educators to monitor the overall progress of each student relative to his/her capacity to mentally and emotionally respond to other people. Moreover, by comparing how students score in their first versus final semester, we could assess any effect of the curriculum on their ability for empathy. In view of the previous finding that first-year students showed higher empathic concern, as compared to advanced-level students (Hen \& Goroshit, 2011), it would seem pertinent to pay closer attention to the impact of curricular content on empathy. It should by all accounts be useful to address empathy (Gerdes \& Segal, 2011), as well as knowledge and regulation of emotion (Morrison, 2007), to increase our understanding of how such skills can be explicitly recognized in students and further developed throughout their education and training in social work.

These conclusions were admittedly drawn on a small sample using a proxy measure for performance in actual practice. Yet the results give a very rough, first glimpse at the specific ways in which empathic ability comes into play in the management of service user cases. As such, the results are compelling enough to prompt further investigation, particularly given the potential usefulness of increased knowledge about what determines the skills needed to take on the oftentimes complex and demanding reality of social work.

\section{Acknowledegment}

The authors are grateful to Ulla Peters for providing the vignette.

\section{Funding}

This work was supported by a grant from the University of Luxembourg. 


\section{References}

Barlow, C., \& Hall, B. L. (2007). 'What about Feelings?': A study of emotion and tension in social work field education. Social Work Education, 26, 399-413. doi:10.1080/ 02615470601081712

Batson, C. D., Early, S., \& Salvarani, G. (1997). Perspective taking: Imagining how another feels versus imagining how you would feel. Personality and Social Psychology Bulletin, 23, 751-8. doi:10.1177/0146167297237008

Batson, C. D., Turk, C. L., Shaw, L. L., \& Klein, T. R. (1995). Information function of empathic concern: Learning that we value the other's welfare. Journal of Personality and Social Psychology, 68, 300-13. doi:10.1037/0022-3514.68.2.300

Buckley, M. (1986). The concept of confiding ties: Implications for social work research and practice. Journal of Social Work Practice, 2, 60-76. doi:10.1080/02650538608414971

Buie, D. H. (1981). Empathy: Its nature and limitations. Journal of American Psychoanalytical Association, 29, 281-307. doi:10.1177/000306518102900201

Carrera, P., Oceja, L., Caballero, A., Munoz, D., Lopez-Pérez, B., \& Ambrona, T. (2013). I feel so sorry! Tapping the joint influence of empathy and personal distress on helping behavior. Motivation and Emotion, 37, 335-45. doi:10.1007/s11031-012-9302-9

Chambers, J. R., \& Davis, M. H. (2012). The role of the self in perspective-taking and empathy: Ease of self-simulation as a heuristic for inferring emphatic feelings. Social Cognition, 30, 153-80. doi:10.1521/soco.2012.30.2.153

Cialdini, R. B., Brown, S. L., Lewis, B. P., Luxe, C., \& Neuberg, S. L. (1997). Reinterpreting the empathy-altruism relationship: When one into one equals oneness. Journal of Personality and Social Psychology, 73, 481-94. doi:10.1037/0022-3514.73.3.481

Coke, J. S., Batson, C. D., \& McDavis, K. (1978). Empathic mediation of helping: A two-stage model. Journal of Personality and Social Psychology, 36, 752-66. doi:10.1037/00223514.36.7.752

Coyle, D., Edwards, D., Hannigan, B., Fothergill, A., \& Burnard, P. (2005). A systematic review of stress among mental health social workers. International Social Work, 48, 201-11. doi:10.1177/0020872805050492

Davis, M. H. (1980). A multidimensional approach to individual differences in empathy. Dissertation Abstracts International, 40, 3480. Retrieved from http://www.uv.es/ friasnav/ Davis_1980.pdf

Davis, M. H. (1983a). Measuring individual differences in empathy: Evidence for a multidimensional approach. Journal of Personality and Social Psychology, 44, 113-26. doi:10.1037/ 0022-3514.44.1.113

Davis, M. H. (1983b). Emphatic concern and the muscular dystrophy telethon: Empathy as a multidimensional construct. Personality and Social Psychology Bulletin, 9, 223-9. doi:10.1177/0146167283092005

Davis, M. H. (1983). The effects of dispositional empathy on emotional reactions in helping: A multidimensional approach. Journal of Personality, 51, 167-84. doi:10.1111/j.14676494.1983.tb00860.x

Davis, M. H., Conklin, L., Smith, A., \& Luce, C. (1996). Effect of perspective-taking on the cognitive representation of persons: A merging of self and other. Journal of Personality and Social Psychology, 70, 713-26. doi:10.1037/0022-3514.70.4.713

Davis, M. H., Hull, J. G., Young, R. D., \& Warren, G. G. (1987). Emotional reactions to dramatic film stimuli: The influence of cognitive and emotional empathy. Journal of Personality and Social Psychology, 52, 126-33. doi:10.1037/0022-3514.52.1.126

Decety, J., \& Jackson, P. L. (2004). The functional architecture of human empathy. Behavioral and Cognitive Neuroscience Reviews, 3, 71-100. doi:10.1177/1534582304267187

Dyregrov, A., \& Mitchell, J. T. (1992). Work with traumatized children: Psychological effects and coping strategies. Journal of Traumatic Stress, 5, 5-17. doi:10.1002/jts.2490050103 
Eisenberg, N. (2000). Emotion, regulation, and moral development. Annual Review of Psychology, 51, 665-97. doi:10.1146/annurev.psych.51.1.665

Engelberg, E., \& Limbach-Reich, A. (2012). After the Bologna reform: Employability of bachelors in social and educational work in Luxembourg. Social Work Education, 31, 807-18. doi:10.1080/02615479.2011.603187

Engelberg, E., \& Limbach-Reich, A. (2015). Prepared enough to practice? Evaluating a study programme in social work. Journal of Social Work. Advance online publication. doi:10.1177/ 1468017315583172

Fahy, A. (2007). The unbearable fatigue of compassion: Notes from a substance abuse counselor who dreams of working at Starbuck's. Clinical Social Work Journal, 35, 199-205. Retrieved from http://www.springer.com/psychology/journal/10615

Forrester, D., McCambridge, J., Waissbein, C., \& Rollnick, S. (2008). How do child and family social workers talk to parents about child welfare concerns? Child Abuse Review, 17, 23-35. doi:10.1002/car.981

Gair, S. (2013). Inducing empathy: Pondering students' (in)ability to empathize with an Aboriginal man's lament and what might be done about it. Journal of Social Work Education, 49, 136-49. doi:10.1080/10437797.2013.755399

Galinsky, A. D., Ku, G., \& Wang, C. S. (2005). Perspective-taking and self-other overlap: Fostering social bonds and facilitating social coordination. Group Processes Intergroup Relations, 8, 109-24. doi:10.1177/1368430205051060

Gallagher, R. M. (2006). Empathy: A timeless skill for the pain medicine toolbox. Pain Medicine, 7, 213-4.

Galuske, M. (2011). Methoden der Sozialen Arbeit: Eine Einführung [Social work methods: An introduction] (Auflage 9). München: Juventa.

Gausel, N. (2011). The importance of emotions in social work: Thematic directions from a national conference. European Journal of Social Work, 14, 287-91. doi:10.1080/ 13691457.2011.578347

Georgi, E., Petermann, F., \& Schipper, M. (2014). Are empathic abilities learnable? Implications for social neuroscientific research from psychometric assessments. Social Neuroscience, 9, 74-81. doi:10.1080/17470919.2013.855253

Gerdes, K. E., \& Segal, E. (2011). Importance of empathy for social work practice: Integrating new science. Social Work, 56, 141-8. doi:10.1093/sw/56.2.141

Grant, L. (2014). Hearts and minds: Aspects of empathy and wellbeing in social work students. Social Work Education, 33, 338-52. doi:10.1080/02615479.2013.805191

Green, S. B. (1991). How many subjects does it take to do a regression analysis. Multivariate Behavioral Research, 26, 499-510. doi:10.1207/s15327906mbr2603_7

Hen, M., \& Goroshit, M. (2011). Emotional competencies in the education of mental health professionals. Social Work Education, 30, 811-29. doi:10.1080/02615479.2010.515680

Kinman, G., \& Grant, L. (2011). Exploring stress resilience in trainee social workers: The role of emotional and social competencies. British Journal of Social Work, 41, 261-75. doi:10.1093/bjsw/bcq088

Kohler, W. (1929). Gestalt psychology. Oxford: Liveright.

Lee, S. A., Guajardo, N. R., Short, S. D., \& King, W. (2010). Individual differences in ocular level empathic accuracy ability: The predictive power of fantasy empathy. Personality and Individual Differences, 49, 68-71. doi:10.1016/j.paid.2010.03.016

Lipps, T. (1913). Zur Einfühlung [To the "feeling into"]. Leipzig: W. Engelmann.

Lymbery, M. (2003). Negotiating the contradictions between competence and creativity in social work education. Journal of Social Work, 3, 99-117. doi:10.1177/1468017303003001007

MacIntyre, G., Green Lister, P., Orme, J., Crisp, B. R., Manthorpe, J., Hussein, S., ... Sharpe, E. (2011). Using vignettes to evaluate the outcomes of student learning: Data from the evalu- 
ation of the new social work degree in England. Social Work Education, 30, 207-22. doi:10.1080/02615479.2011.540397

Marvin, R. S., Greenberg, M. T., \& Mossler, D. G. (1976). The early development of conceptual perspective taking: Distinguishing among multiple perspectives. Child Development, 47, 511-4. doi:10.2307/1128810

Maus, F., Nodes, W., \& Röh, D. (2008). Schlüsselkompetenzen der Sozialen Arbeit: Für die Tätigkeitsfelder Sozialarbeit und Sozialpädagogik [Key competencies in the social professions: The areas of social work and social pedagogy]. Schwalbach: Wochenschau Verlag.

Mooradian, T. A., Davis, M., \& Matzler, K. (2011). Dispositional empathy and the hierarchical structure of personality. The American Journal of Psychology, 124, 99-109. doi:10.5406/ amerjpsyc.124.1.0099

Morrison, T. (2007). Emotional intelligence, emotion and social work: Context, characteristics, complications and contribution. British Journal of Social Work, 37, 245-63. doi:10.1093/ bjsw/bcl016

Napoli, M., \& Bonifas, R. (2011). From theory towards empathic self care: Creating a mindful classroom for social work students. Social Work Education, 30, 635-49. doi:10.1080/ 02615479.2011 .586560

National Association of Social Workers. (2008). Code of ethics of the national association of social workers. Washington, DC: NASW Press.

Nijnatten, C., Hoogsteder, M., \& Suurmond, J. (2001). Communication in care and coercion: Institutional interactions between family supervisors and parents. British Journal of Social Work, 31, 705-20. doi:10.1093/bjsw/31.5.705

Nomura, K., \& Akai, S. (2012). Empathy with fictional stories: Reconsideration of the Fantasy scale of the Interpersonal Reactivity Index. Psychological Reports, 110, 304-14. doi:10.2466/ 02.07.09.11.PR0.110.1.304-314

Parkinson, B., \& Manstead, A. S. R. (1993). Making sense of emotion in stories and social life. Cognition and Emotion, 7, 295-323. doi:10.1080/02699939308409191

Paschall, M. J., Fishbein, D. H., Hubal, R. C., \& Eldreth, D. (2005). Psychometric properties of virtual reality vignette performance measures: A novel approach for assessing adolescents' social competency skills. Health Education Research, 20, 61-70. doi:10.1093/her/cyg103

Paulus, C. (2009). Der Saarbrücker persönlichkeitsfragebogen SPF (IRI) zur messung von Empathie [The Saarbrucken personality questionnaire SPF (IRI) for the measurement of empathy]. Retrieved from http://psydok.sulb.uni-saarland.de/volltexte/2009/2362

Poulou, M. (2001). The role of vignettes in the research of emotional and behavioral difficulties. Emotional and Behavioral Difficulties, 6, 50-62. doi:10.1080/13632750100507655

Toi, M., \& Batson, D. C. (1982). More evidence that empathy is a source of altruistic motivation. Journal of Personality and Social Psychology, 43, 281-92. doi:10.1037/00223514.43.2.281

Wampold, B. E. (2010). The basics of psychotherapy: An introduction to theory and practice. Vol. xiv. Theories of psychotherapy series. Washington, DC: American Psychological ssociation, pp. 3-14.

Wispé, L. (1986). The distinction between sympathy and empathy: To call forth a concept, a word is needed. Journal of Personality and Social Psychology, 50, 314-21. doi:10.1037/00223514.50.2.314 